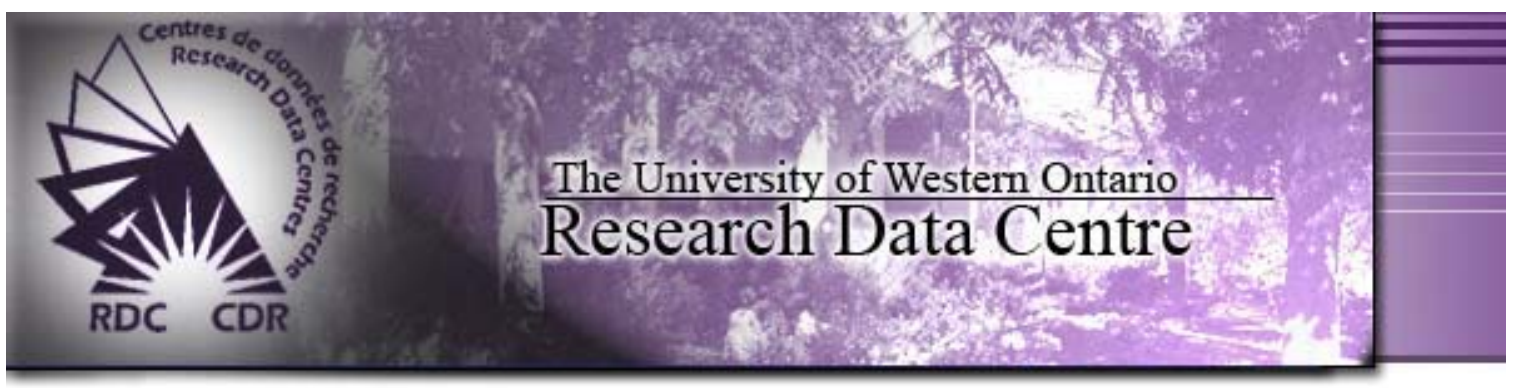

May 2007 Volume 1, Number 2

\title{
The Acculturation of Canadian Immigrants: Determinants of Ethnic Identification with the Host Society
}

Economic success does not necessarily make immigrants feel more "Canadian", nor does the lack of it necessarily make them feel less so, according to a recent study by David Walters, Kelli Phythian and Paul Anisef on the increasingly important question of immigrant assimilation and integration in Canada.

Their findings fly in the face of the generally held assumption that economic and cultural assimilation go hand in hand - that as immigrants gradually integrate into the workforce and start earning more, they begin to adopt the customs, values and attitudes of the host country; then, as their values and attitudes converge with those of the host country, they are eventually able to participate fully in economic life.

This study uses Statistics Canada's 2002 Ethnic Diversity Survey (EDS), accessed at the UWO Research Data Centre, to investigate whether this relationship actually exists. It explores whether immigrants who achieve work, education and socio-economic success are more likely to identify themselves as Canadian as those who do not.

At the survey, immigrants were asked to give the "ethnic or cultural group or groups to which they felt they belonged" - with "Canadian" as one of the groups. The researchers used this information in an innovative way, to distinguish between two separate forms of acculturation described in the literature: assimilation and integration.

An assimilated immigrant has adopted the customs and values of the host country to the extent that he is indistinguishable from the native-born population. An integrated immigrant has become an active member of the host country while at the same time maintaining a distinct ethnic identity.

In their sample of working immigrants (which excludes those who were interviewed in French, for reasons explained in the paper), almost one-sixth (16\%) declared "Canadian" as their only ethnic identity (classified as assimilated); just under one quarter (24\%) reported "Canadian" and another ethnic identity (classified as integrated). The majority (61\%) did not give "Canadian" as an ethnic identity (classified as neither assimilated nor integrated).

Comparing these three groups, while controlling for a host of socio-economic and demographic factors, the researchers were astonished to find that income and employment characteristics had no apparent influence on the way immigrants reported their ethnic identity. Neither higher earnings nor the type of occupation made them more likely to consider themselves Canadian. Their analysis, in other words, gave no evidence of the link between economic and cultural assimilation assumed in the theoretical literature. 
Instead, their feeling of belonging was linked to socio-cultural factors: religious affiliation, perceived discrimination, visible minority status, language use and friends. Assimilation was more common among immigrants who had no religious affiliation, who had not been discriminated against, and who spoke an official language at home. They were more likely to vote, and least likely to be surrounded by friends from the same country of origin. Whereas South Asian immigrants were most likely to declare "Canadian" as their only ethnic identity, black immigrants were least likely to include it as a group to which they belonged.

Above all, however, time appears to be "of the essence". It may take years of gradual adaptation to their new country before immigrants start to feel they belong; but, with the years, this sense of belonging does seem to grow. As the graph shows, with each year since their arrival in Canada, immigrants were increasingly likely to report "Canadian" as the only group with which they identify.

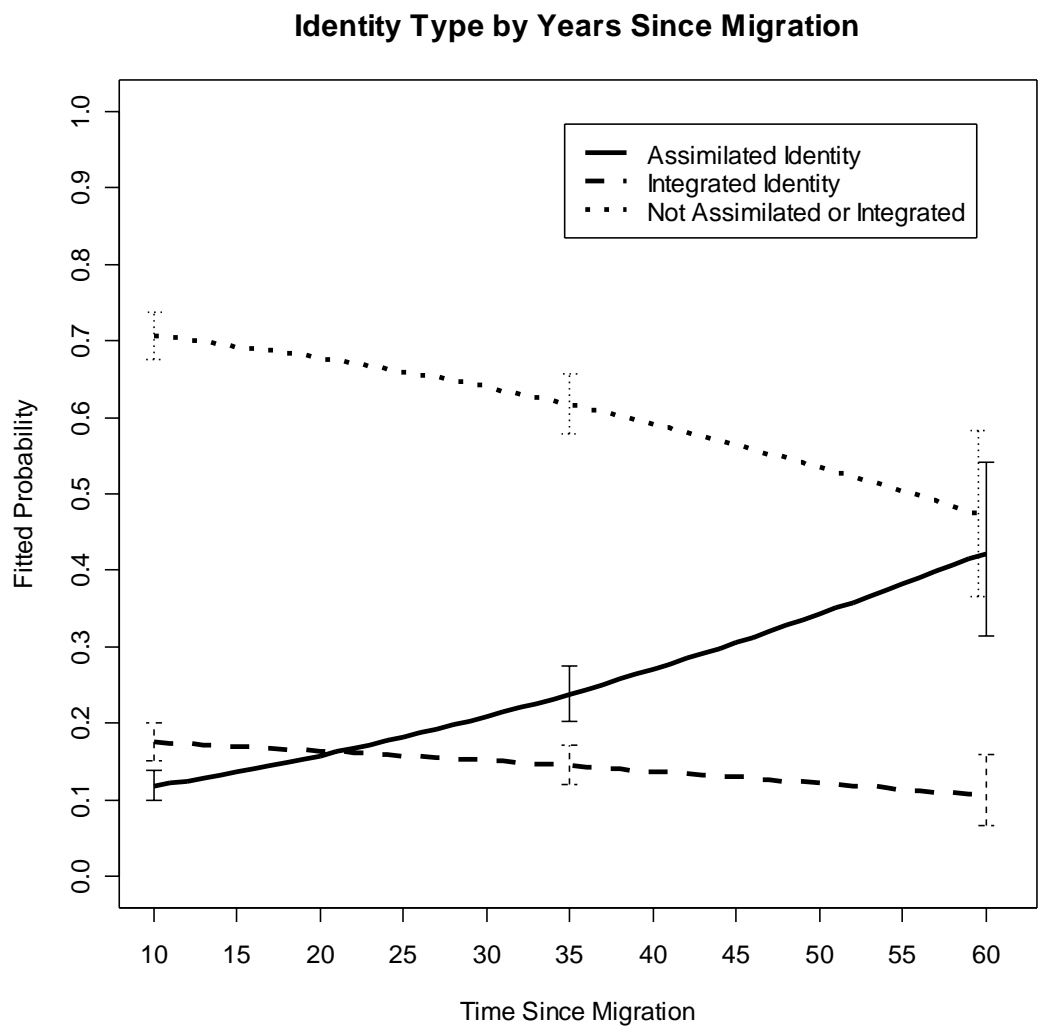

These findings are both intriguing and reassuring. Intriguing because of the lack of support for the pervasive assumption that economic and cultural assimilation go together. Reassuring because it is crucial for national unity that immigrants identify with their new homeland. Given the current trend of economic decline among newcomers in Canada, it is fortunate that this identification is not too dependent on the level of economic integration.

Based on the paper: Walters, David, Kelly Phythian, and Paul Anisef. The Acculturation of Canadian Immigrants: Determinants of Ethnic Identification with the Host Society. Canadian Review of Sociology 44 (1): 37-64.

*Note: *Data for this study came from the Ethnic Diversity Survey. The analysis was conducted at the UWO Regional Statistics Canada Research Data Centre. The Research Data Centre program is part of an initiative by Statistics Canada, SSHRC, CIHR and university consortia to strengthen Canada's social research capacity. 